\title{
Application of infrared portable sensor technology for predicting perceived astringency of acidic whey protein beverages
}

\author{
Ting Wang, ${ }^{*}$ Siow-Ying Tan, $†$ William Mutilangi, $†$ Marcal Plans, ${ }^{*}$ and Luis Rodriguez-Saona* \\ *Department of Food Science and Technology, The Ohio State University, Columbus 43210 \\ †Pepsi-Cola Company, Valhalla, NY 10595
}

\begin{abstract}
Formulating whey protein beverages at acidic $\mathrm{pH}$ provides better clarity but the beverages typically develop an unpleasant and astringent flavor. Our aim was to evaluate the application of infrared spectroscopy and chemometrics in predicting astringency of acidic whey protein beverages. Whey protein isolate (WPI), whey protein concentrate (WPC), and whey protein hydrolysate (WPH) from different manufacturers were used to formulate beverages at $\mathrm{pH}$ ranging from 2.2 to 3.9. Trained panelists using the spectrum method of descriptive analysis tested the beverages providing astringency scores. A portable Fourier transform infrared spectroscopy attenuated total reflectance spectrometer was used for spectra collection that was analyzed by multivariate regression analysis (partial least squares regression) to build calibration models with the sensory astringency scores. Beverage astringency scores fluctuated from 1.9 to 5.2 units and were explained by $\mathrm{pH}$, protein type (WPC, WPI, or WPH), source (manufacturer), and their interactions, revealing the complexity of astringency development in acidic whey protein beverages. The WPC and WPH beverages showed an increase in astringency as the $\mathrm{pH}$ of the solution was lowered, but no relationship was found for WPI beverages. The partial least squares regression analysis showed strong relationship between the reference astringency scores and the infrared predicted values (correlation coefficient $>0.94$ ), giving standard error of cross-validation ranging from 0.08 to 0.12 units, depending on whey protein type. Major absorption bands explaining astringency scores were associated with carboxylic groups and amide regions of proteins. The portable infrared technique allowed rapid prediction of astringency of acidic whey protein beverages, providing the industry a novel tool for monitoring sensory characteristics of whey-containing beverages.
\end{abstract}

Received May 5, 2016.

Accepted August 3, 2016.

${ }^{1}$ Corresponding author: rodriguez-saona.1@osu.edu
Key words: whey protein, acidic beverages, astringency, infrared spectroscopy, chemometrics

\section{INTRODUCTION}

The use of whey proteins in beverages is growing because of their high nutritional value, wide functional versatility, and association with health benefits such as weight control and muscle building. Beverage clarity increases at low pH (Miller, 2007); however, astringency perception also increases at low $\mathrm{pH}$ (Ye et al., 2011). The astringency development is a significant product challenge limiting consumer acceptance (Sano et al., 2005; Beecher et al., 2008).

Astringency is described as the complex of sensations due to shrinking, drawing, or puckering of the epithelium as a result of exposure to substances such as alums or tannins (Gibbins and Carpenter, 2013). Astringent molecules are commonly plant-based products, most commonly tannins, and the most usual form of exposure to these products worldwide is through polyphenols in drinking tea (Gibbins and Carpenter, 2013). Other astringent compounds include acids and metal alums and other dehydrating agents such as alcohols that create the subjective feeling of astringency (Gibbins and Carpenter, 2013). The mechanism of astringency is attributed to polyphenolic compounds (Haslam et al., 1988) binding to and precipitating specific salivary proteins (Baxter et al., 1997; Kallithraka et al., 1998) and limiting lubricity in the mouth (Clifford, 1996). Gibbins and Carpenter (2013) attribute astringency development to a loss of mucosal lubrication by altering the salivary bulk, saliva rheology, and saliva pellicle, leading to an increase of friction in the oral cavity. Studies to identify the mechanism driving astringency in acidic whey protein beverages have been inconclusive; however, some mechanisms have been proposed. Beecher et al. (2008) suggested that whey proteins become positively charged at low $\mathrm{pH}$, and could bind and aggregate with salivary proteins (Sano et al., 2005; Vardhanabhuti et al., 2010). However, Lee and Vickers (2008) suggested that the astringency of acidic whey protein beverages 
was possibly caused by their high acidity. Ye et al. (2011) reported that protein aggregation that causes astringency at $\mathrm{pH} 3.4$ and $\mathrm{pH} 2.0$ can be attributed to whey protein and salivary protein interacting via electrostatic interactions at $\mathrm{pH} 3.4$, whereas only salivary proteins undergo aggregation at $\mathrm{pH} 2.0$.

Currently, astringency of whey protein beverages is determined by trained sensory panelists, a benchmark in qualifying and quantifying sensory properties; however, it is laborious, expensive, and time consuming. The demand for protein-fortified foods and beverages is increasing steadily. A quick and reliable method to predict astringency in low $\mathrm{pH}$ beverages will enable efficiency in early ingredient screening and product development. Mid-infrared spectroscopy (4,000-700 $\mathrm{cm}^{-1}$ ) is a rapid, sensitive, and high-throughput method commonly used in analysis of food components. The output is a molecular "fingerprint" spectrum of the absorption bands corresponding to frequencies of vibrations between the bonds of the atoms making up the material. Optical technology is been rapidly developed and instruments are already available commercially as portable, handheld, and micro-devices (Ellis and Goodacre, 2006). Ellis et al. (2015) summarized the developments in portable and handheld or remote sensor devices (or both) for on/at-line analysis at points of vulnerability along the complex food supply networks. Advantages of these sensor devices include low cost, small size, compactness, robustness, and ease of operation for in-field routine analysis. Furthermore, specific bands arising from group vibrations may be assigned to known specific chemical entities in most cases. Developments in the field of multivariate techniques have been prompted by the need of reliable, accurate, robust, and simple methods for routine analysis of spectroscopic data (Udelhoven et al., 2000). Partial least squares regression (PLSR) method is the most commonly used regression algorithm in molecular spectroscopy. The algorithm seeks for the best decomposition of the $\mathrm{X}$ matrix that will best describe the Y matrix (Roggo et al., 2007). The PLSR method derives its usefulness from its ability to analyze noisy and collinear data (Wold et al., 2001) combining the features of principal component analysis and multilinear regression to compress a large number of variables into a few latent variables [partial least squares (PLS) factors] by attempting to explain the maximum variance in both the spectra and reference data sets (Karoui and De Baerdemaeker, 2007).

Mid-infrared spectroscopy has been widely used for assessing milk quality such as predicting milk composition (Lynch et al., 2006), protein composition (De Marchi et al., 2009a; Bonfatti et al., 2011), milk coagulation properties (De Marchi et al., 2009b), milk fat composition (Rutten et al., 2009; Soyeurt et al., 2011), and major mineral contents (Soyeurt et al., 2009). Because the value and functionality of whey protein products are largely affected by their composition, infrared spectroscopy combined with chemometrics has shown potential in correlating various functional properties of whey and casein hydrolysates (van der Ven et al., 2002) and characterizing whey protein powders [whey protein concentrate (WPC), whey protein isolate (WPI), and whey protein hydrolysate $(\mathbf{W P H})]$ based on their unique infrared profile showing well-separated clustering among the powder samples (Wang et al., 2015). In contrast, a limited number of infrared applications have been reported for predicting perceived astringency (Ferrer-Gallego et al., 2013) with major emphasis directed toward quantification of tannins in wine (Edelmann and Lendl, 2002; Fernandez and Agosin, 2007; Noypitaka et al., 2015).

Our objective was to develop a predictive model for estimating astringency in acidic whey protein beverages based on the relationship between the perceived intensity of the target astringency stimuli and unique spectral fingerprints from a portable infrared spectrometer. In addition, we will explore the protein chemical modifications associated with perceived astringency in acidic beverages based on the unique PLS regression vector information associated with the underlying chemistry of the models.

\section{MATERIALS AND METHODS}

\section{Formulation of Whey Protein Beverages and Sensory Astringency Scores}

Whey protein beverages were produced from WPI, WPC, or WPH powders obtained from 9 different commercial manufacturers for a total of 19 different whey protein products. Beverages contained $5 \mathrm{~g}$ of protein per $8 \mathrm{oz}(21.1 \mathrm{~g} / \mathrm{L})$ equivalent, sucrose $(8 \% \mathrm{wt} / \mathrm{wt})$ was added in each formulation, and phosphoric acid $(40 \%)$ or potassium carbonate $(20 \%)$ solutions were used to adjust the $\mathrm{pH}$ of individual beverage sample to target. Beverage samples were formulated from whey protein powders [WPI (9), WPC (6), and WPH (4)] and adjusted to different $\mathrm{pH}$ values ranging from 2.2 to 3.9 (Table 1). Each sample was coded with a 3-digit number and vacuum packed in a glass bottle. Beverage samples were maintained at $4^{\circ} \mathrm{C}$ until spectra collection using FTIR. A validation set was produced with 3 different powder sources of WPI, and one WPH along with sucrose $(8 \% \mathrm{wt} / \mathrm{wt})$, and their $\mathrm{pH}$ were adjusted to 3.0 and 3.8 .

Quantitative sensory test on all whey protein beverage samples was conducted at the Sensory Service Center in North Carolina State University. Ten panelists 
Table 1. Sensory astringency scores perceived from whey protein beverage samples under various $\mathrm{pH}$ values ${ }^{1,2}$

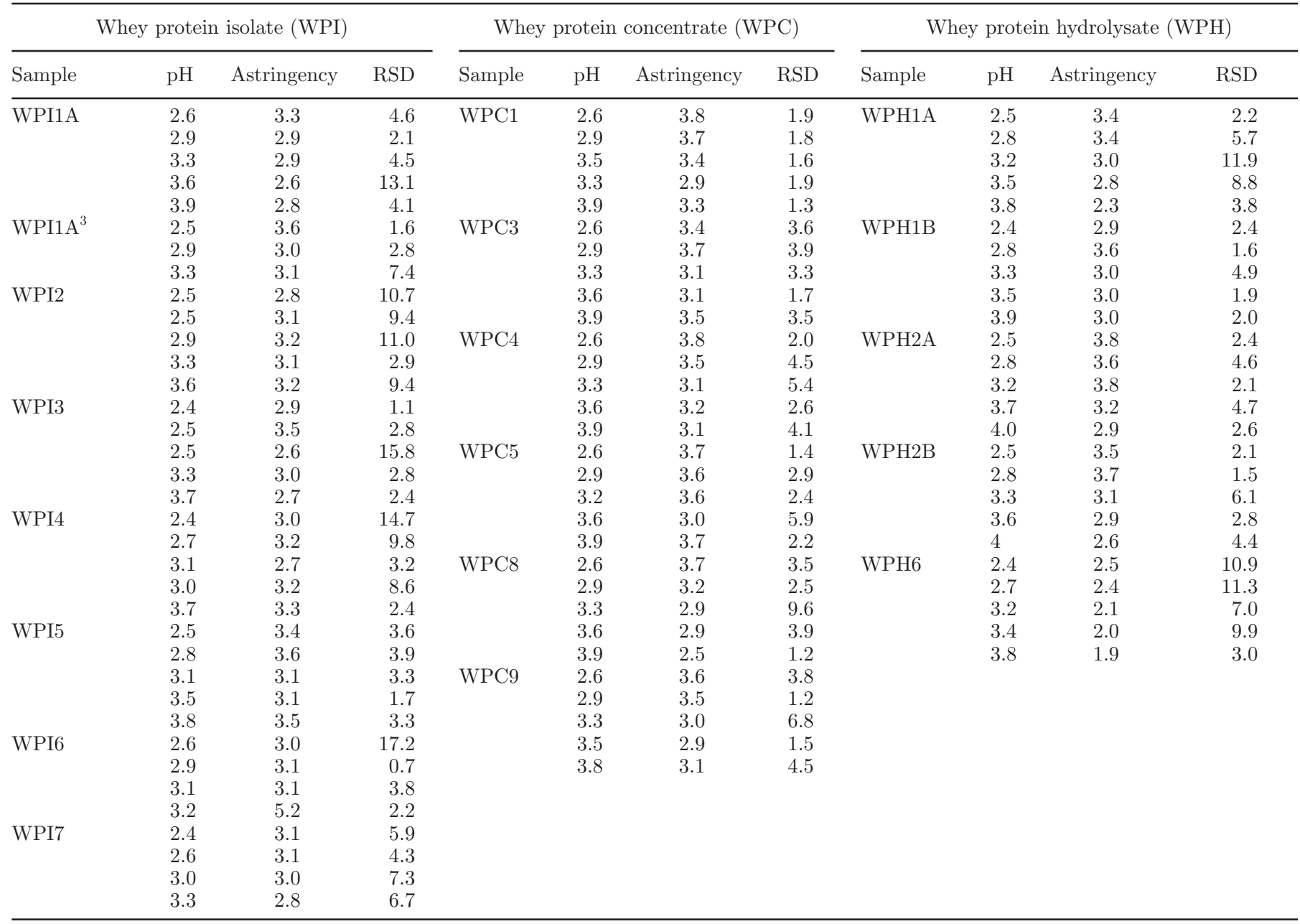

${ }^{1}$ Different numbers represent different whey protein suppliers; different letters represent different products from the same supplier. RSD = relative standard deviation.

${ }^{2}$ Four replicates were evaluated for each beverage sample. Eleven panelists participated in each session.

${ }^{3}$ Beverages manufactured with the same whey protein product in different years (2012 and 2013).

trained in the Spectrum method of descriptive analysis for generation of quantitative data conducted the sensory evaluation (Beecher et al., 2008). A 0- to 15-point universal intensity scale was used to rate astringency intensity, where rating of 0 indicated no perceived astringency and 15 indicated the highest possible intensity of astringency. Four replications were performed for each beverage sample.

\section{Infrared Spectral Acquisition}

Spectra collection from each beverage sample was done using a portable infrared system (Cary 630 FTIR Spectrometer, Agilent Technologies, Santa Clara, CA) coupled with a diamond attenuated total reflectance (ATR) accessory and equipped with a temperature- stabilized deuterated triglycine sulfate detector and ZnSe beam splitter. Spectrum collection included placing $5 \mu \mathrm{L}$ of the beverage sample on the center of diamond crystal, and then vacuum was applied for $2 \mathrm{~min}$ to remove the majority of the water, producing a film on top of diamond crystal. The infrared spectrum were collected using MicroLab software (Agilent Technologies) operating in the wavenumber ranges from 4,000 to $700 \mathrm{~cm}^{-1}$ with resolution of $4 \mathrm{~cm}^{-1}$ and 64 scans were co-added to enhance signal to noise ratio. Duplicate spectra were collected for each sample.

\section{Chemometric Analysis}

Partial least squares regression was performed to build calibration models to correlate the reference 
sensory astringency score to the infrared spectral information. Partial least squares regression is a bilinear regression analysis method that extracts a small number of orthogonal factors (latent variables) that are linear combinations of the spectral $(\mathrm{X})$ variables and uses these factors as regressors for the analyte's concentration (Y-variable). The method explains the covariance between $\mathrm{X}$ and $\mathrm{Y}$ remaining after the previous $a-1$ factors have been estimated and subtracted (Bjørsvik and Martens, 2008). Partial least squares regression uses the concentration information (Y-variable) actively in determining how the regression factors are computed from the spectral data matrix $(\mathrm{X})$, reducing the effect of irrelevant X-variations in the calibration model (Haaland and Thomas, 1988; Segtnan and Isaksson, 2000). This capability provides a more information-rich data set of reduced dimensionality and eliminates data noise, resulting in more accurate and reproducible calibration models (Wold et al., 2001). Before analysis, preprocessing methods such as vector-length normalization and Savitzky-Golay smoothing filter (35 gap size) were used to minimize the effect of band intensities (Barnes et al., 1989) and increase the signal-to-noise ratio of the spectra by keeping the relevant variation (Rinnan et al., 2009). The PLSR models were evaluated in terms of scores, loading vectors, regression vector, standard error of calibration, standard error of cross-validation (SECV) representing the magnitude of error expected when independent samples are predicted using the model, coefficient of correlation (r-value), and outlier diagnostics based on the error of prediction and leverage on the sample in the model. The PLSR calibration model was cross-validated (leave-one-out approach) to determine the optimal number of latent variables and the prediction ability of the models (Wold et al., 2001). The chemometric software Pirouette V4.5 (Infometrix, Bothell, WA) was used to develop PLSR models.

\section{Analysis of Variance}

The relationship between the sensory trait astringency and $\mathrm{pH}$ was analyzed using a linear model with main factors type of whey protein, manufacturers, and their interactions. The lineal model was defined as

$$
\begin{aligned}
y_{i j}=\mu+\alpha_{i}+\tau_{j} & +\gamma_{i j}+\left(\theta+\beta_{1, i}+\beta_{2, j}+\beta_{3, i j}\right) \\
& \times \mathrm{pH}+\varepsilon_{i j},
\end{aligned}
$$

where $\mu$ is the grand mean, $\alpha_{i}$ is the effect of the main factor related to types of protein $(i), \tau_{j}$ is the effect of the main factor related to manufacturers $(j), \gamma_{i j}$ is the effect of the interaction between type of protein (i) and manufacturers $(j), \theta$ is the grand slope between astringency and $\mathrm{pH}, \beta_{1, i}$ is the effect on the slope of the main factor types of whey protein $(i), \beta_{2, j}$ is the effect on the slope of the main factor manufacturers $(j), \beta_{3, i j}$ is the effect on the slope of the interaction between type of protein $(i)$ and manufacturers $(j)$, and $\varepsilon_{i j}$ is the error of the model distributed as $N \sim(0, \sigma)$, where $N$ indicates a normal distribution centered at 0 and $\sigma$ is the standard deviation of the error. The results of the model were analyzed considering an unbalanced data using type III sum of squares. The linearity of the model was tested by the analysis of the residuals. Statistical analysis was done using an open source statistical software R (http://www.r-project.org) and the packages AGRICOLAE and CAR (Fox and Weisberg, 2011; Mendiburu, 2014).

\section{RESULTS AND DISCUSSION}

\section{Perceived Astringency Scores for Whey Protein Beverages}

Development of astringency in whey proteins beverages manufactured at low $\mathrm{pH}$ (3 to 3.5 ) is thought to be related to protein concentration (Kelly et al., 2010), the high level of acid needed to lower the $\mathrm{pH}$ of a protein solution (Lee and Vickers, 2008), precipitation of proteins at their isoelectric points (Sano et al., 2005), electrostatic interactions between whey proteins and saliva proteins removing the lubricating effect of specific saliva proteins (Beecher et al., 2008; Vardhanabhuti et al., 2010), and salivary protein aggregation at $\mathrm{pH}$ 2.0 (Ye et al., 2011). A total of 9 whey protein suppliers (18 different products) were used in the preparation of acidic beverages. The whey protein powder ingredients were obtained from different suppliers and product lines introducing variability associated with whey separation technologies, whey sources (acid vs. sweet whey), and processing treatments. The perceived astringency scores of whey protein beverage samples prepared at various acidic $\mathrm{pH}$ levels (Table 1) showed that whey protein beverage samples exhibited different astringency response when their $\mathrm{pH}$ values decreased from 3.9 to 2.2 (Figure 1). Statistical analysis (Table 2) showed that astringency scores in acidic whey protein beverages were explained by $\mathrm{pH}$, whey protein type (WPC, WPI, or WPH), whey protein source (manufacturer $)$, and their interactions $(P$-value $<0.001)$, revealing the complexity of astringency development in acidic whey protein beverages. Beverages produced with WPI powders had the lowest astringency scores ranges (3.06 $\pm 0.31)$, followed by WPC $(3.31 \pm 0.37)$, whereas WPH showed the largest variability $(2.96 \pm 0.57)$. 
(A)
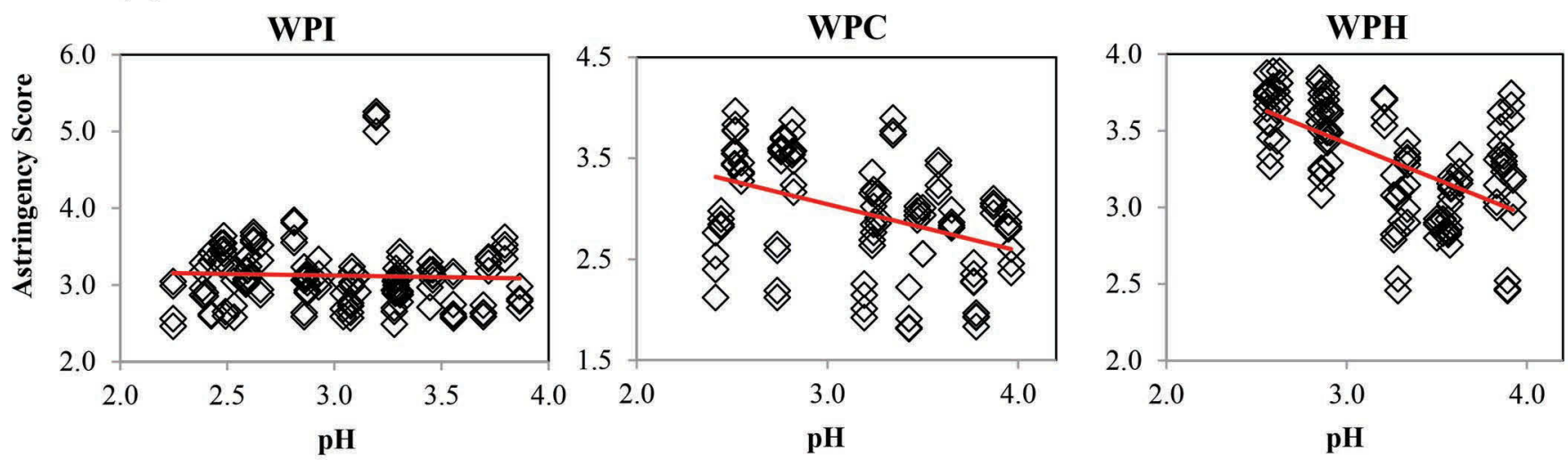

(B)
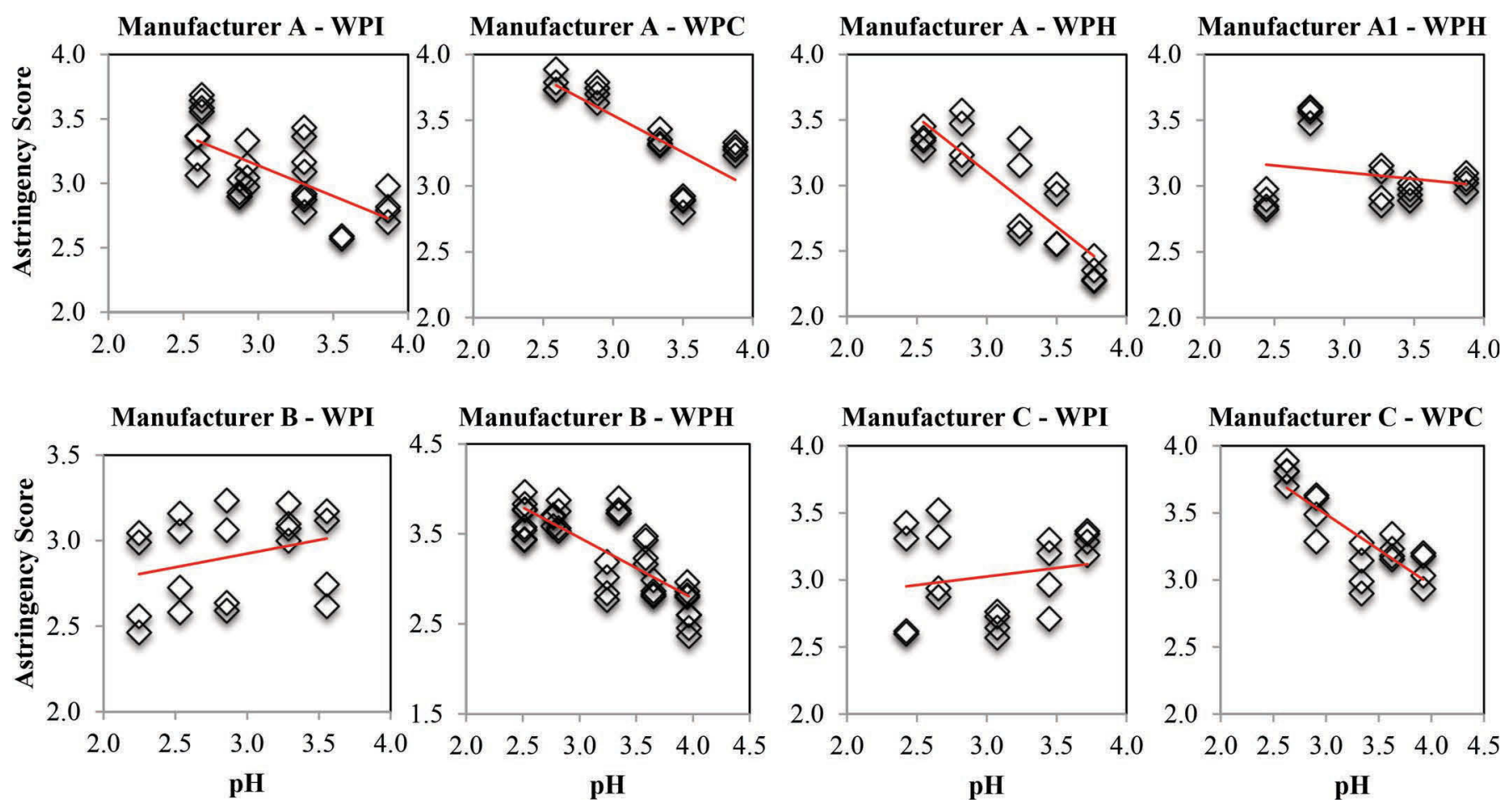

Figure 1. Scatterplots between perceived astringency scores and $\mathrm{pH}$ based on (A) whey protein type [whey protein isolate (WPI), whey protein concentrate (WPC), and whey protein hydrolysate (WPH)] and (B) selected manufacturers. Only selected ingredient manufacturers are presented, and a similar letter represents the same manufacturer. Color version available online.

Figure 1A shows that astringency development in WPI beverages had negligible correlation with $\mathrm{pH}$, whereas WPH and WPC beverages showed an effect of $\mathrm{pH}$ on perceived astringency scores, showing that increasing beverage acidity resulted in an increase in astringency. Our data also showed that whey protein products played an important role in astringency perception (Table 1). The $\mathrm{pH}$ effect on astringency perception in WPI beverages was only evident for WPI-1 (Figure 1B), whereas all other WPI products showed no significant effect; instead, most WPH (4 out of 5) and WPC (4 out of 6 ) beverages showed similar trends of intensifying their perceived astringency scores as the $\mathrm{pH}$ was lowered. Figure 1B illustrates the strong effect of product type on perceived astringency in acidic beverages manufactured by 3 different companies. Beecher et al. (2008) evaluated the effect of $\mathrm{pH}$ on astringency development in whey protein solutions and found that whey protein solutions exhibited higher astringency at acidic $\mathrm{pH}(\sim 3.4)$ than neutral $\mathrm{pH}(6.8)$, but found a 


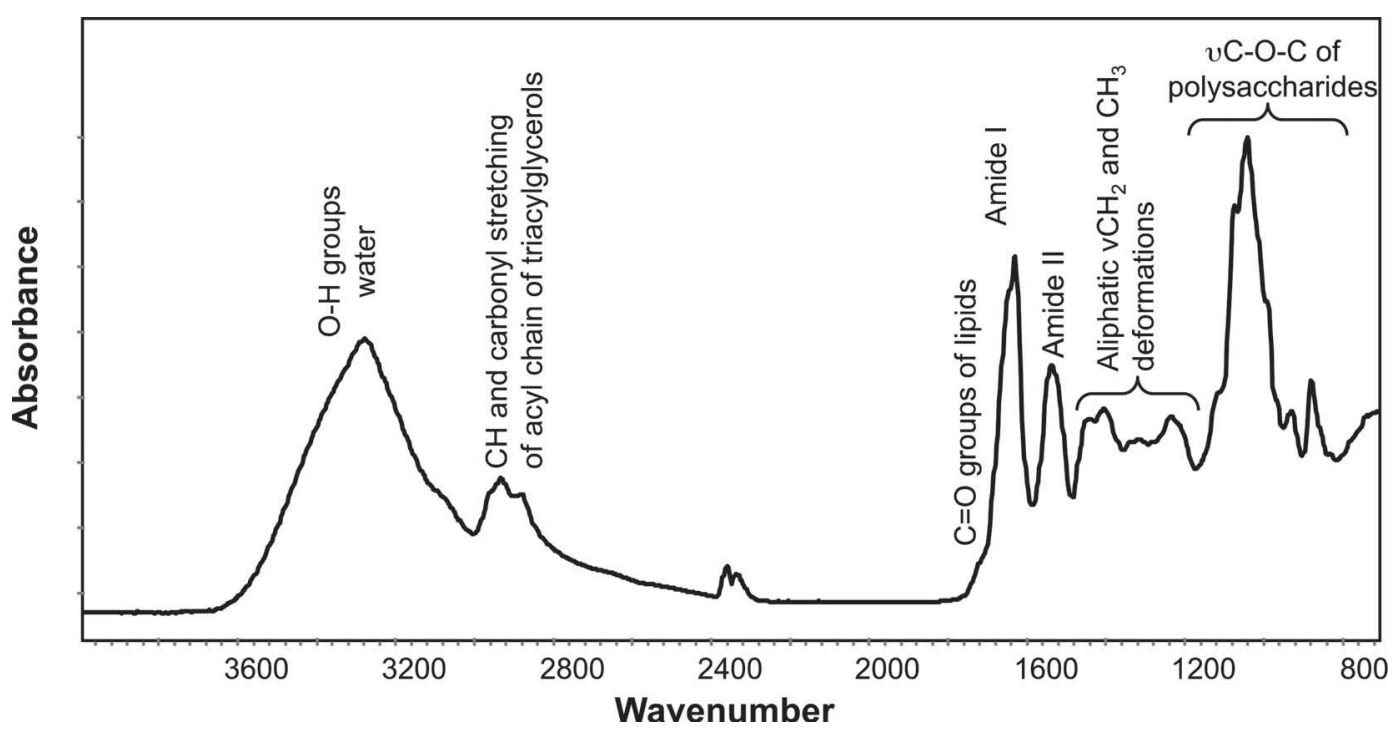

Figure 2. Representative attenuated total reflectance (ATR) mid-infrared spectrum of a whey protein (WPI) beverage sample that was vacuum dried onto the ATR crystal to form a film.

decrease in astringency between $\mathrm{pH} 3.4$ and 2.6 that coincided with an increase in sourness (Beecher et al., 2008).

\section{Partial Least Squares Regression Analysis for Predicting Perceived Astringency}

The new generation of portable/handheld optical systems (FTIR spectrometers) incorporate analytical precision for chemical identification and quantitation with spectral resolution equivalent to that of benchtop instruments (Wilkerson et al., 2013), allowing for in-plant analysis because these units can be easily carried and transferred to different locations. The infrared spectrum of a whey protein beverage film (Figure 2) in the information-rich region of 1,800 to $700 \mathrm{~cm}^{-1}$ showed the important contributions of the broad bands at 1,650 and $1,520 \mathrm{~cm}^{-1}$ associated with the amide I and am- ide II group vibrations of proteins (Barth, 2007). The bands in the 1,400 to $1,200 \mathrm{~cm}^{-1}$ region resulted from the deformation bending of $\mathrm{C}-\mathrm{H}$ groups of aliphatic hydrocarbons and amide III stretching vibrations of proteins and the band at $1,390 \mathrm{~cm}^{-1}$ corresponded to the stretching of $\mathrm{C}=\mathrm{O}$ in the $\mathrm{COO}$ - groups (Barth, 2000). The intense bands between 1,200 and $900 \mathrm{~cm}^{-1}$ resulted from the $\mathrm{C}-\mathrm{O}-\mathrm{C}$ and $\mathrm{C}-\mathrm{O}$ vibrations of carbohydrates and were prevalent in beverage samples (Figure 2) as they contained added sugars in the ingredient matrix.

The performance of models generated from spectra collected by using a portable infrared spectrometer equipped with an ATR accessory were evaluated for predicting perceived astringency of whey protein beverages manufactured at various $\mathrm{pH}$ values. Table 3 shows that best PLSR model performances were obtained using spectra collected in the 1,780 to $1,480 \mathrm{~cm}^{-1}$ for WPI, WPC, and WPH beverages, resulting in excel-

Table 2. Multiple linear regression using $\mathrm{pH}$ levels and protein types as predictor and astringency as response ${ }^{1}$

\begin{tabular}{lcccrc}
\hline Item & df & $\begin{array}{c}\text { Sum of } \\
\text { squares }\end{array}$ & $\begin{array}{c}\text { Mean } \\
\text { square }\end{array}$ & $F$-value & $P(>F)$ \\
\hline Type (WPC, WPI, WPH) & 2 & 8.33 & 4.16 & 45.47 & $<0.001$ \\
Manufacturers & 9 & 11.08 & 1.23 & 13.44 & $<0.001$ \\
Type: Manufacturers & 4 & 21.90 & 5.47 & 59.75 & $<0.001$ \\
pH & 1 & 5.40 & 5.40 & 58.94 & $<0.001$ \\
pH: Type & 2 & 2.07 & 1.03 & 11.31 & $<0.001$ \\
pH: Manufacturers & 9 & 6.22 & 0.69 & 7.54 & $<0.001$ \\
pH: Type: Manufacturers & 4 & 5.75 & 1.43 & 15.70 & $<0.001$ \\
Error & 330 & 24.43 & 0.074 & & \\
\hline
\end{tabular}

${ }^{1}$ For each protein types from different protein sources, 5 different $\mathrm{pH}$ levels ranging from 2.2 to 3.9 were used as explanatory variable. Whey protein isolate (WPI), whey protein concentrate (WPC), whey protein hydrolysate (WPH). 
Table 3. Partial least squares regression calibration and cross-validation results of multivariate models developed for whey protein beverages ( $\mathrm{pH} 2.4$ to 3.9) using a portable Fourier transform infrared spectroscopy attenuated total reflectance spectrometer ${ }^{1}$

\begin{tabular}{lcccccc}
\hline $\begin{array}{l}\text { Whey } \\
\text { protein }^{2}\end{array}$ & $\begin{array}{c}\text { Sample } \\
\text { number }\end{array}$ & Factor $^{4}$ & SECV $^{5}$ & $\mathrm{R}_{\mathrm{CV}^{6}}{ }^{6}$ & $\mathrm{SEC}^{7}$ & $\mathrm{R}_{\text {cal }}{ }^{8}$ \\
\hline WPI & 35 & 4 & 0.08 & 0.94 & 0.08 & 0.95 \\
WPC & 29 & 4 & 0.12 & 0.91 & 0.12 & 0.95 \\
WPH & 25 & 2 & 0.10 & 0.97 & 0.09 & 0.97
\end{tabular}

${ }^{1}$ The same spectral range $\left(1,780\right.$ to $\left.1,480 \mathrm{~cm}^{-1}\right)$ in the infrared region was used for mode development.

${ }^{2}$ Whey protein powder used for beverage formulation. Whey protein isolate (WPI), whey protein concentrate (WPC), whey protein hydrolysate (WPH).

${ }^{3}$ Sample number $=$ whey protein beverage samples used in developing the models.

${ }^{4}$ Factor $=$ number of latent variables used in the model and determined by cross-validation.

${ }^{5} \mathrm{SECV}=$ standard error of cross-validated calibration model.

${ }^{6} \mathrm{R}_{\mathrm{CV}}=$ correlation coefficient of cross-validated calibration model.

${ }^{7} \mathrm{SEC}=$ standard error of calibration model.

${ }^{8} \mathrm{R}_{\text {cal }}=$ correlation coefficient of calibration model

lent correlations $(\mathrm{r}>0.91)$ between infrared spectra and perceived astringency scores (Figures $3 \mathrm{~A}, 3 \mathrm{~B}$, and 3C) and SECV ranging from 0.08 to 0.12 . Models for predicting astringency in beverages formulated with WPI excluded 2 outliers (WPI-3 at pH 2.5 and WPI-6 at $\mathrm{pH} 3.2$ ) because of their high leverage and residual diagnostics. Two beverage lots of WPI-3 were produced at $\mathrm{pH} 2.5$ and gave very different perceived astringency scores by panelists (Table 1), and the beverages that were identified as outliers showed a large coefficient of variability (relative standard deviation). The outlier in WPI-6 at pH 3.2 showed unusually high astringency scores (5.2) compared with the other WPI beverage samples with astringency scores ranging from 2.6 to 3.6. Overall, the best calibration performances for predicting sensory astringency score based on ATR-infrared spectra were obtained for WPI [correlation coefficient of cross-validated calibration model $\left(\mathbf{R}_{\mathrm{CV}}\right)=0.94$, $\mathrm{SECV}=0.08]$ followed by WPH $\left(\mathrm{R}_{\mathrm{CV}}=0.97, \mathrm{SECV}=\right.$ $0.10)$ and $\mathrm{WPC}\left(\mathrm{R}_{\mathrm{CV}}=0.91, \mathrm{SECV}=0.12\right)$ beverages.

Loading plots for PLSR models (Figure 3D) confirmed the importance of the carbonyl stretching vibration $\left(\sim 1,720 \mathrm{~cm}^{-1}\right)$ and amide II (centered at 1,540 $\mathrm{cm}^{-1}$ ) regions in explaining the variance associated with astringency scores for whey protein beverages, indicating that carboxylic acids from acidic AA and modifications in protein secondary structure played an important role in regulating astringency generated from whey protein beverages. The regression vectors for WPI, WPC, and WPH models showed the importance of the $\nu(\mathrm{C}=\mathrm{O})$ vibration of the protonated carboxyl group of AA Asp and Glu absorbing in a spectral 1,710 to $1,760 \mathrm{~cm}^{-1}$ region (Barth, 2000), supporting the theory that electrostatic interactions among whey and saliva proteins can disrupt the salivary film and alter lubrication, leading to exposure of the pellicle and reducing its abil- ity to protect and lubricate the epithelium (Gibbins and Carpenter, 2013). The signal in the 1,580 to 1,500 $\mathrm{cm}^{-1}$ region is related to amide II band representing the combined $\delta(\mathrm{N}-\mathrm{H})$ and $\nu(\mathrm{C}-\mathrm{N})$ contributions of the AA side-chain vibrations of proteins (Kong and $\mathrm{Yu}$, 2007). The band shifts from a broad signal centered at $1,556 \mathrm{~cm}^{-1}$ (WPI), $1,534 \mathrm{~cm}^{-1}$ (WPC), and $1,510 \mathrm{~cm}^{-1}$ $(\mathrm{WPH})$ as amide II bands are sensitive to the secondary structure content of a protein (Barth, 2007). The band at $\sim 1,564 \mathrm{~cm}^{-1}$ originates from the antisymmetric COO- stretching vibration of the side chain carboxylate groups of glutamate, implying ionic interactions in the $\beta$-sheet conformation (Ismail et al., 1992). The band at centered at $1,540 \mathrm{~cm}^{-1}$ is typical of the amide II vibration and the band at $1,510 \mathrm{~cm}^{-1}$ for $\mathrm{WPH}$ can be assigned to Tyr side-chain ring vibrations or an antiparallel pleated sheet structure (Pelton and McLean, 2000).

The region between 1,660 and $1,600 \mathrm{~cm}^{-1}$ was removed for WPC and WPI models because it did not provide relevant information as this region is influenced by residual water absorbance $\left(1,640 \mathrm{~cm}^{-1}\right)$. The WPH and WPC models showed similar loadings patterns in explaining perceived astringency in acidic beverages (Figure 3D). The regression vector of WPI models (Figure $3 \mathrm{D}$ ) was more complex, with a broad band in the 1,780 to $1,660 \mathrm{~cm}^{-1}$ and a unique band at $1,685 \mathrm{~cm}^{-1}$ that has been associated with the formation of $\beta$-sheet structures upon aggregation due to irreversible intermolecular self-association under conditions of low $\mathrm{pH}$ with mild heating (Ismail et al., 1992). As indicated previously, astringency development in beverages prepared with WPI showed minimal change in astringency with $\mathrm{pH}$ and this might be associated with the processing of the samples. The PLS regression vector explaining the variance in WPI models (Figure 3D) showed major 
differences related to formation of $\beta$-sheet structures upon protein aggregation $\left(1,685\right.$ and $\left.1,556 \mathrm{~cm}^{-1}\right)$ and might limit further protein conformation modifications as the $\mathrm{pH}$ of the beverage was changed.
We have shown the ability of ATR-infrared to correlate with protein modifications as related to astringency development and the importance of the region dominated by acidic AA and the amide-II protein region.
A)

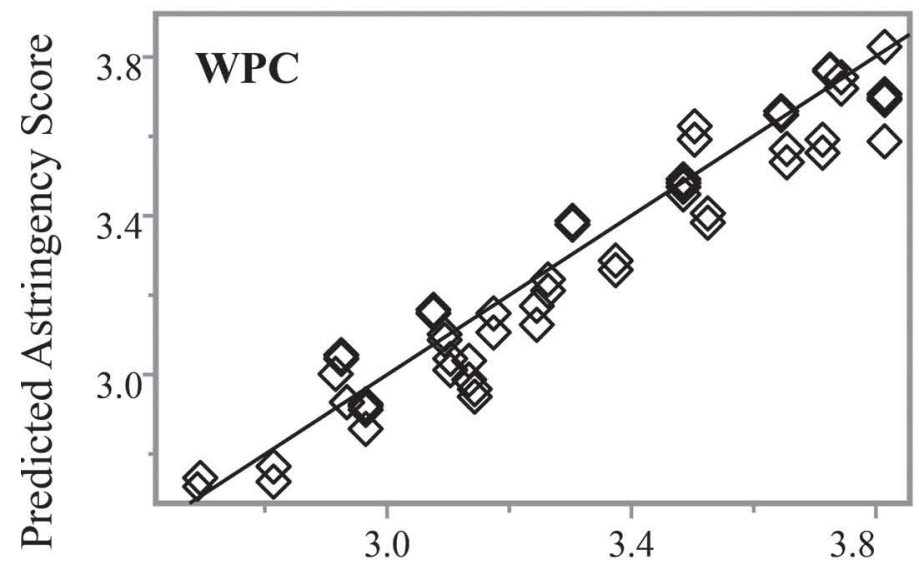

B)

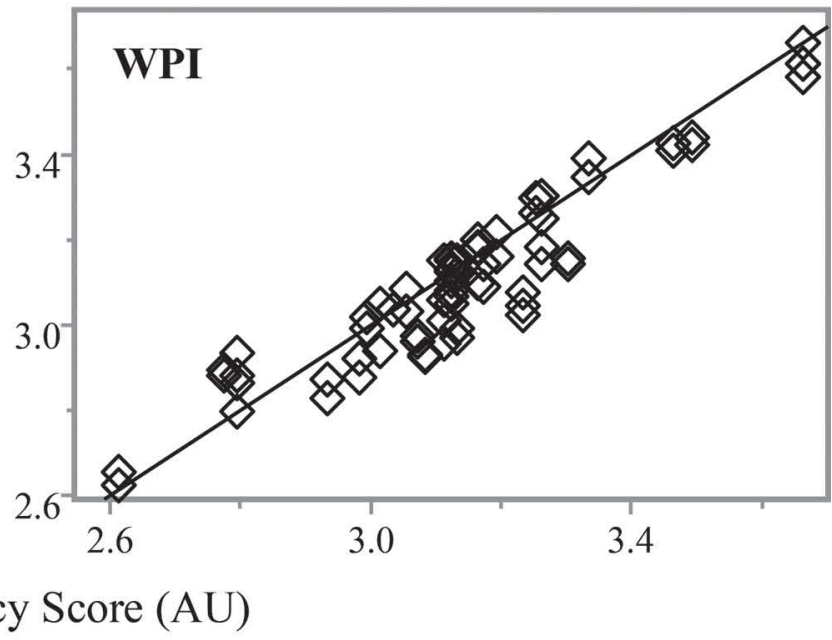

D)

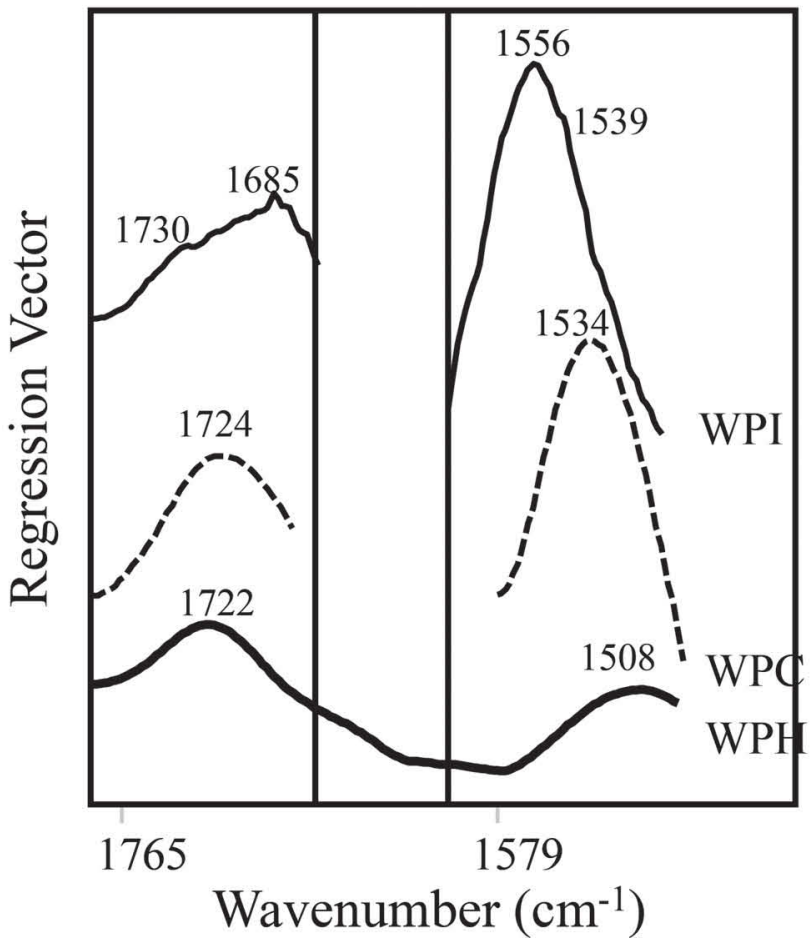

Figure 3. Partial least squares regression (PLSR) correlation plots based on the infrared spectra of whey protein [whey protein concentrate (WPC; A), whey protein isolate (WPI; B), and whey protein hydrolysate (WPH; C)] beverage samples manufactured at various pH (ranging from 2.2 to 3.9). (D) PLSR vectors for whey protein models generated using spectral data from a portable Fourier transform infrared spectroscopy attenuated total reflectance infrared spectrometer. The PLSR coefficients are useful for interpretation purposes by providing informationrich data relevant to spectral frequencies associated with explaining most of the model variance; thus, the higher the magnitude of their absolute values, the more they contribute to the model. $\mathrm{AU}=$ arbitrary units. 
Table 4 shows the astringency predictions of an independent validation set of samples using the models developed using WPI and WPH beverages manufactured at different $\mathrm{pH}$ values. Astringency predictions for whey protein isolate beverages showed very good agreement with the sensory scores except for WPI-3 beverages that showed a $10 \%$ deviation from the target value but showed the same proportion in astringency perception when the $\mathrm{pH}$ was acidified from 3.8 to 3.0 . We need to point out that a WPH sample (Table 4) gave a $15 \%$ deviation from the target sensory value (3.36); however, our predicted score was in agreement with its replicated WPH treatment using the same powder ingredient and prepared under the similar conditions $(\mathrm{pH} 3)$.

The portable infrared technique generated robust calibration models for predicting astringency scores in whey protein beverages. Overall, WPI beverages showed the highest \% relative standard deviation among panelists (0.7 to $17 \%$ ) compared with WPH (1.5 to $12 \%$ ) and WPC (1 to 7\%). Taking into consideration that the standard deviation among panelists for predicting astringency scores was on average 0.16 (WPI), 0.13 (WPH), and 0.11 (WPC) units, the predictive ability of our infrared models with SECV $<0.12$ units showed good reliability, because the uncertainty in the reference scores will also be a source of variability for the regression models. By maximizing the variance from whey protein types, manufacturer sources (different processing techniques), and acidic $\mathrm{pH}$ values, robust calibration models to predict astringency were generated for whey protein beverages.

\section{CONCLUSIONS}

Astringency development of acidic whey protein beverages is complex and appears to be associated with modifications on protein secondary structure. The $\mathrm{pH}$ alone is not the sole factor regulating astringency in whey protein beverages, but whey protein powder type (WPI, WPC, and WPH) and product lines played very important roles in explaining astringency scores by panelists. Infrared spectroscopy combined with pattern recognition analysis allowed for the rapid $(\sim 3 \mathrm{~min}$ analysis time) and robust prediction of astringency scores of WPI, WPC, and WPH beverages. Spectra collected from a portable infrared unit equipped with a single bounce diamond ATR crystal gave correlation coefficients $>0.91$ and SECV of 0.1 units for predicting astringency in acidic whey protein beverages. The most important bands explaining the astringency scores were associated with the carboxylic functional groups (COO-) and amide II, which relate to modifications occurring in the secondary structure of the native protein and possibly unmasking acidic AA. Our results indicated
Table 4. Prediction values of astringency in whey protein beverages using infrared spectra and calibration models generated by a portable attenuated total reflectance infrared unit (validation set)

\begin{tabular}{llcc}
\hline & & \multicolumn{2}{c}{ Validation set } \\
\cline { 3 - 4 } $\begin{array}{l}\text { Whey protein } \\
\text { type }\end{array}$ & $\mathrm{pH}$ & Predicted score & Sensory score \\
\hline WPI_1 & 3 & $3.50 \pm 0.02$ & $3.45 \pm 0.09$ \\
& & $3.43 \pm 0.03$ & $3.51 \pm 0.11$ \\
& 3.8 & $3.54 \pm 0.01$ & $3.63 \pm 0.14$ \\
WPI_2 & 3 & $3.59 \pm 0.02$ & $3.80 \pm 0.20$ \\
& 3.8 & $3.67 \pm 0.01$ & $3.65 \pm 0.18$ \\
WPI_3 & 3 & $3.42 \pm 0.02$ & $3.26 \pm 0.22$ \\
& 3.8 & $3.18 \pm 0.02$ & $3.81 \pm 0.08$ \\
WPH_1 & 3 & $2.75 \pm 0.02$ & $3.52 \pm 0.19$ \\
& & $2.78 \pm 0.01$ & $3.28 \pm 0.12$ \\
& 3.8 & $2.56 \pm 0.02$ & $2.33 \pm 0.25$ \\
& & $2.59 \pm 0.01$ & $2.14 \pm 0.07$ \\
\hline
\end{tabular}

${ }^{1} \mathrm{WPI}=$ whey protein isolate; $\mathrm{WPH}=$ whey protein hydrolysate.

that differences in astringency of acidic whey protein beverages might be associated with modifications to protein structure due to a combined effect of acid $\mathrm{pH}$ and whey manufacturing processes. Overall, simple and rapid protocols were developed based on infrared technology for predicting astringency of acidic whey protein beverages, providing tools to quickly monitoring astringency development, allowing selection of ingredients to improve overall sensory profile and boost consumer acceptance of whey protein food products.

\section{ACKNOWLEDGMENTS}

The authors acknowledge the financial support of the Pepsi-Cola Company (Valhalla, NY; project 60033048).

\section{REFERENCES}

Barnes, R. J., M. S. Dhanoa, and S. J. Lister. 1989. Standard normal variate transformation and de-trending of near-infrared diffuse reflectance spectra. Appl. Spectrosc. 43:772-777.

Barth, A. 2000. The infrared absorption of amino acid side chains. Prog. Biophys. Mol. Biol. 74:141-173.

Barth, A. 2007. Infrared spectroscopy of proteins. Biochim. Biophys. Acta 1767:1073-1101.

Baxter, N. J., T. H. Lilley, E. Haslam, and M. P. Williamson. 1997. Multiple interactions between polyphenols and a salivary prolinerich protein repeat result in complexation and precipitation. Biochemistry 36:5566-5577.

Beecher, J. W., M. A. Drake, P. J. Luck, and E. A. Foegeding. 2008. Factors regulating astringency of whey protein beverages. J. Dairy Sci. 91:2553-2560.

Bjørsvik, H. R., and H. Martens. 2008. Data analysis: Calibration of NIR instruments by PLS regression Chapter 9 in Handbook of Near Infrared Analysis. 3rd ed. D. Burns and E. Ciurczak, ed. CRC Press, Taylor and Francis Group, Boca Raton, FL.

Bonfatti, V., G. Di Martino, and P. Carnier. 2011. Effectiveness of mid-infrared spectroscopy for the prediction of detailed protein composition and contents of protein genetic variants of individual milk of Simmental cows. J. Dairy Sci. 94:5776-5785.

Clifford, M. N. 1996. Astringency. Proc. Phytochem Soc. Eur. 41:87107. 
De Marchi, M., V. Bonfatti, A. Cecchinato, G. Di Martino, and P. Carnier. 2009a. Prediction of protein composition of individual cow milk using mid-infrared spectroscopy. Ital. J. Anim. Sci. 8(Suppl. 2):399-401.

De Marchi, M., C. C. Fagan, C. P. O'Donnell, A. Cecchinato, R. Dal Zotto, M. Cassandro, M. Penasa, and G. Bittante. 2009b. Prediction of coagulation properties, titratable acidity, and $\mathrm{pH}$ of bovine milk using mid-infrared spectroscopy. J. Dairy Sci. 92:423-432.

Edelmann, A., and B. Lendl. 2002. Toward the optical tongue: Flowthrough sensing of tannin-protein interactions based on FT-MIR spectroscopy. J. Am. Chem. Soc. 124:14741-14747.

Ellis, D. I., and R. Goodacre. 2006. Metabolic fingerprinting in disease diagnosis: Biomedical applications of infrared and Raman spectroscopy. Analyst (Lond.) 131:875-885.

Ellis, D. I., H. Muhamadali, S. A. Haughey, C. T. Elliott, and R. Goodacre. 2015. Point-and-shoot: Rapid quantitative detection methods for on-site food fraud analysis-Moving out of the laboratory and into the food supply chain. Anal. Methods 7:9401-9414.

Fernandez, K., and E. Agosin. 2007. Quantitative analysis of red wine tannins using Fourier-transform mid-infrared spectrometry. J. Agric. Food Chem. 55:7294-7300.

Ferrer-Gallego, R., J. M. Hernandez-Hierro, J. C. Rivas-Gonzalo, and M. T. Escribano-Bailon. 2013. Evaluation of sensory parameters of grapes using near infrared spectroscopy. J. Food Eng. 118:333-339.

Fox, J., and S. Weisberg. 2011. An $\{\mathrm{R}\}$ Companion to Applied Regression. 2nd ed. SAGE Publications Inc., Thousand Oaks, CA.

Gibbins, H. L., and G. H. Carpenter. 2013. Alternative mechanisms of astringency-What is the role of saliva? J. Texture Stud. 44:364375 .

Haaland, D. M., and E. V. Thomas. 1988. Partial least-squares methods for spectral analysis: 1. Relation to other multivariate calibration methods and the extraction of qualitative information. J. Anal. Chem. 60:1193-1202.

Haslam, E., T. H. Lilley, and L. G. Butler. 1988. Natural astringency in food stuffs - A molecular interpretation. Crit. Rev. Food Sci. Nutr. 27:1-40

Ismail, A. A., H. H. Mantsh, and T. T. Wong. 1992. Aggregation of chymotrypsinogen: Portrait by infrared spectroscopy. Biochim. Biophys. Acta 1121:183-188.

Kallithraka, S., J. Bakker, and M. N. Clifford. 1998. Evidence that salivary proteins are involved in astringency. J. Sens. Stud. 13:29-43.

Karoui, R., and J. De Baerdemaeker. 2007. A review of the analytical methods coupled with chemometrics tools for the determination of the quality and identity of dairy products. Food Chem. 102:621-640

Kelly, M., B. Vardhanabhuti, P. J. Luck, M. A. Drake, J. Osborne, and E. A. Foegeding. 2010. Role of protein concentration and protein saliva-interactions in the astringency of whey proteins at low $\mathrm{pH}$. J. Dairy Sci. 93:1900-1909.

Kong, J., and S. Yu. 2007. Fourier transform infrared spectroscopic analysis of protein secondary structures. Acta Biochim. Biophys. Sin. (Shanghai) 39:549-559.

Lee, C. A., and Z. M. Vickers. 2008. The astringency of whey protein beverages is caused by their acidity. Int. Dairy J. 18:1153-1156.

Lynch, J. M., D. M. Barbano, M. Schweisthal, and R. Fleming. 2006. Pre-calibration evaluation procedures for mid-infrared milk analyzers. J. Dairy Sci. 89:2761-2774.

Mendiburu, F. 2014. Agricolae: Statistical Procedures for Agricultural Research. R package version 1.1-8. http://CRAN.R-project.org/ package $=$ agricolae
Miller, G. 2007. A sporting attitude. Prepared Foods 176:91-92.

Noypitaka, S., A. Terdwongworakula, K. Krisanapookb, and S. Kasemsumran. 2015. Evaluation of astringency and tannin content in 'Xichu' persimmons using near infrared spectroscopy. Int. J. Food Prop. 18:1014-1028.

Pelton, J. T., and L. R. McLean. 2000. Spectroscopic methods for analysis of protein secondary structure. Anal. Biochem. 277:167176.

Rinnan, A., F. van den Berg, and S. B. Engelsen. 2009. Review of the most common pre-processing techniques for near-infrared spectra. Trends Analyt. Chem. 28:1201-1222.

Roggo, Y., P. Chalus, L. Maurer, C. Lema-Martinez, A. Edmond, and N. Jent. 2007. A review of near infrared spectroscopy and chemometrics in pharmaceutical technologies. J. Pharm. Biomed. Anal. 44:683-700.

Rutten, M. J. M., H. Bovenhuis, K. A. Hettinga, H. J. F. van Vanlenberg, and J. A. M. van Arendonk. 2009. Predicting bovine milk fat composition using infrared spectroscopy based on milk samples collected in winter and summer. J. Dairy Sci. 92:6202-6209.

Sano, H., T. Egashira, Y. Kinekawa, and N. Kitabatake. 2005. Astringency of bovine milk whey protein. J. Dairy Sci. 88:2312-2317.

Segtnan, V. H., and T. Isaksson. 2000. Evaluating near infrared techniques for quantitative analysis of carbohydrates in fruit juice model systems. J. Near Infrared Spectrosc. 8:109-116.

Soyeurt, H., D. Bruwier, J. M. Romnee, N. Gengler, C. Bertozzi, D. Veselko, and P. Dardenne. 2009. Potential estimation of major mineral contents in cow milk using mid-infrared spectrometry. J. Dairy Sci. 92:2444-2454

Soyeurt, H., F. Dehareng, N. Gengler, S. McParland, E. Wall, D. P. Berry, M. Coffey, and P. Dardenne. 2011. Mid-infrared prediction of bovine milk fatty acids across multiple breeds, production systems, and countries. J. Dairy Sci. 94:1657-1667.

Udelhoven, T., D. Naumann, and J. Schmitt. 2000. Development of a hierarchical classification system with artificial neural networks and FT-IR spectra for the identification of bacteria. Appl. Spectrosc. 54:1471-1479.

van der Ven, C., S. Muresan, H. Gruppen, D. B. A. D. Bont, K. B. Merck, and A. G. J. Voragen. 2002. FTIR spectra of whey and casein hydrolysates in relation to their functional properties. J. Agric. Food Chem. 50:6943-6950.

Vardhanabhuti, B., M. A. Kelly, P. J. Luck, M. A. Drake, and E. A. Foegeding. 2010. Roles of charge interactions on astringency of whey proteins at low pH. J. Dairy Sci. 93:1890-1899.

Wang, T., S. Y. Tan, W. Mutilangi, D. P. Aykas, and L. E. RodriguezSaona. 2015. Authentication of whey protein powders by portable mid-infrared spectrometers combined with pattern recognition analysis. J. Food Sci. 80:C2111-C2116.

Wilkerson, E. D., G. E. Anthon, D. M. Barrett, G. F. G. Sayajon, A. M. Santos, and L. E. Rodriguez-Saona. 2013. Rapid assessment of quality parameters in processing tomatoes using hand-held and benchtop infrared spectrometers and multivariate analysis. J. Agric. Food Chem. 61:2088-2095.

Wold, S., M. Sjöström, and L. Eriksson. 2001. PLS-regression: A basic tool of chemometrics. Chemom. Intell. Lab. Syst. 58:109-130.

Ye, A., C. Streicher, and H. Singh. 2011. Interactions between whey proteins and salivary proteins as related to astringency of whey protein beverages at low pH. J. Dairy Sci. 94:5842-5850. 